\section{Case Reports in Ophthalmology}

Case Rep Ophthalmol 2016;7:296-302

DOI: $10.1159 / 000446151$
Publisned onine: June 2, 2016

(C) 2016 The Author(s)

Published by S. Karger AG, Basel www.karger.com/cop

This article is licensed under the Creative Commons Attribution-NonCommercial 4.0 International License (CC BY-NC) (http://www.karger.com/Services/OpenAccessLicense). Usage and distribution for commercial purposes requires written permission.

\title{
Glaucoma Management in Carotid Cavernous Fistula
}

\author{
Silvia Calafiore ${ }^{\mathrm{a}} \quad$ Andrea Perdicchi $^{\mathrm{a}} \quad$ Gianluca Scuderi $^{\mathrm{a}}$ \\ Maria Teresa Contestabile ${ }^{\mathrm{a}}$ Solmaz Abdolrahimzadeh $^{\mathrm{b}}$ \\ Santi Maria Recupero ${ }^{a}$ \\ ${ }^{a}$ Ophthalmology Unit, NESMOS Department, Sant'Andrea Hospital, Sapienza University of \\ Rome, Rome, Italy; ${ }^{b}$ Ophthalmology Unit, Azienda Policlinico Umberto I, Sapienza \\ University of Rome, Rome, Italy
}

\section{Keywords}

Carotid cavernous fistula - Glaucoma - Management - Ocular hypertension · Multidisciplinary treatment

\begin{abstract}
Carotid cavernous fistulas (CCF) are vascular communications between the carotid artery and the cavernous sinus. Ophthalmologists are called to diagnose and manage the condition in cases that present with ocular features. A 73-year-old female was referred to our glaucoma center clinic. Eight years before, she had started receiving medication for glaucoma and had undergone laser iridotomy, but a satisfactory management of intraocular pressure (IOP) had not been achieved. The patient was complaining of intermittent diplopia, bilateral proptosis, and conjunctival chemosis over the past 6 months. Best-corrected visual acuity in the right (OD) and left eye (OS) was $9 / 10$ and $10 / 10$, respectively. Visual field testing showed slight paracentral field defects mostly in OS. IOP was $20 \mathrm{~mm} \mathrm{Hg}$ in OD and $34 \mathrm{~mm} \mathrm{Hg}$ in OS. We referred the patient to neuroradiology, and MRI angiography revealed a CCF with angiographic classification of Cognard grade 2. Closure of the CCF by transarterial embolization was performed in the neuroradiology department. One week following the procedure, the clinical signs of diplopia, proptosis, and conjunctival chemosis had greatly improved, and IOP was reduced to $12 \mathrm{~mm} \mathrm{Hg} \mathrm{OD} \mathrm{and} 19 \mathrm{~mm} \mathrm{Hg}$ in OS. Glaucoma treatment was maintained with topical brimatoprost, brinzolamide, and timolol. Owing to the risk of vision loss associated with vascular stasis, retinal ischemia, and high IOP, ophthalmologists must be aware of
\end{abstract}




\section{Case Reports in Ophthalmology}

Case Rep Ophthalmol 2016;7:296-302

(c) 2016 The Author(s). Published by S. Karger AG, Basel www.karger.com/cop

Calafiore et al.: Glaucoma Management in Carotid Cavernous Fistula

the clinical features of CCF and should request appropriate imaging studies such as MRI angiography in order to confirm the diagnosis and plan multidisciplinary treatment.

(C) 2016 The Author(s)

Published by S. Karger AG, Basel

\section{Introduction}

Carotid cavernous fistulas (CCF) are vascular communications between the carotid artery and the cavernous sinus $[1,2]$. Although CCF management is formally in the area of interest of neuroradiology and neurosurgery, ophthalmologists are frequently called to diagnose and manage the condition in cases first presenting with ocular features. In fistulas draining directly into the ophthalmic veins, the diagnosis may be straightforward, presenting with symptoms of pulsatile proptosis, diplopia, marked episcleral congestion and chemosis, and a red eye [3]. However, in posterior dural draining CCF (through the superior/inferior petrous sinuses), symptoms may be mild and difficult to interpret (white-eye syndrome). In both cases, an orbital bruit may be audible with careful auscultation [2].

Other features of CCF include venous and arterial stasis that may cause retinal and choroidal changes such as conjunctiva arterialization, anterior segment ischemia with neovascular changes, papilledema, retinal venous dilatation, retinal hemorrhage, and central retinal vein occlusion, which require appropriate treatment [4]. Orbital venous stasis and extraocular muscle engorgement may cause restricted ocular motility associated with diplopia. Alternatively, ophthalmoplegia/diplopia may also be caused by decreased perfusion and ischemia of cranial nerves in the intracavernous sinus [1,3]. The involvement of both eyes (OU; or in rare cases only the fellow eye in isolation) is explained by the communication of the cavernous sinuses $[1,3]$.

In this report, glaucoma management in a 73-year-oldfemale with a CCF is presented.

\section{Case Presentation}

A 73-year-old female was referred to our glaucoma center clinic for management of glaucoma and to undergo evaluation for selective laser trabeculoplasty, Argon laser trabeculoplasty, and/or cataract surgery. Eight years before, she had started receiving medication for ocular hypertension that included a combination of topical bimatoprost, dorzolamide, brimonidine, and oral acetazolamide $(250 \mathrm{mg})$ with unsatisfactory results and had undergone laser iridotomy 2 months before. Past medical history was significant for chronic obstructive pulmonary disease, depressive mood disorder, and treatment for breast cancer.

On presentation, the patient was complaining of intermittent diplopia, bilateral proptosis, and conjunctival chemosis over the past 6 months. Best-corrected visual acuity in the right eye (OD) was $9 / 10$ (corrected with $-1.5 \mathrm{cyl} / 100$ axis) and uncorrected visual acuity in the left eye (OS) was 10/10. Clinical examination revealed the following: proptosis of OU, respectively 20 and $22 \mathrm{~mm}$ in OD and OS, diplopia, conjunctival chemosis in OU but more severe in OD (fig. 1a), diffuse corneal epithelial abrasion due to proptosis in OU, narrow iridocorneal angle in OU (Shaffer grade 2), initial lens nuclear sclerosis OU, and two viable laser iridotomies in OS. Intraocular pressure (IOP) measured with Icare tonometry was $20 \mathrm{~mm} \mathrm{Hg}$ in OD and $34 \mathrm{~mm} \mathrm{Hg}$ in OS [5]. Fundus examination with optic nerve head evaluation was normal with no signs of venous or arterial congestion and absence of hemorrhages or exudates in OU. Optical coherence tomography (OCT) of the optic discs showed normal peri- 
papillary retinal nerve fiber thicknesses in OU (fig. 2a). Visual-field testing showed slight paracentral field defects mostly in OS, but with substantially normal glaucoma hemifield test in OU (fig. 2b).

Based on the clinical signs (proptosis, diplopia, and conjunctival chemosis), examination results (substantially normal optic nerve heads and visual fields in OU), and the patient history (8 years of ocular hypertension that was well controlled with medical therapy in the past), the clinical presentation was considered to be atypical and consistent with a secondary glaucoma of unknown etiology, so we decided to perform further investigations before considering treatment. As the first step an orbital auscultation was performed in OU in order to look for any bruit that is typical of CCF, but the results were doubtful and uncertain. We then referred the patient to neuroradiological consultation and investigation of the cerebral vasculature. MRI angiography revealed a CCF with angiographic classification of Cognard grade 2 (fig. 3a).

Closure of the CCF by transarterial embolization was performed in the neuroradiology department, using detachable balloon embolization by introducing an intravascular microcatheter into the intracavernous portion of the internal carotid artery and placing a stent in the fistula. Finally, a postoperative control arteriography was performed, showing considerable reduction of the flow at the fistula (fig. $3 \mathrm{~b}$ ).

One week following the procedure, the patient was seen at our clinic. The clinical signs of diplopia, proptosis, and conjunctival chemosis were greatly reduced (fig. 1b). IOP was reduced to $12 \mathrm{~mm} \mathrm{Hg} \mathrm{OD}$ and $19 \mathrm{~mm} \mathrm{Hg}$ in OS on topical treatment with brimatoprost, brinzolamide, and timolol. The values of IOP remained stable for the following 6 months.

\section{Discussion}

The increase of IOP in CCF is mainly caused by increased episcleral and vortex vein pressure. In such cases, closure of the fistula and normalization of circulation has a favorable result in reducing IOP. In other cases, glaucoma may be caused by iris neovascularization due to decreased retinal perfusion or vascular engorgement and edema of the choroid and ciliary body, causing a forward movement of the iris/lens resulting in pupil block glaucoma $[6,7]$. IOP measurement, visual field testing, and optic nerve head evaluation are of paramount importance, and the patient must be closely followed up in this manner [8-10]. OCT, other than being used in macular pathology, is also helpful for the early diagnosis of peripapillary and macular retinal nerve fiber changes [11]. Furthermore, the ophthalmologist should request appropriate imaging studies such as MRI angiography in order to confirm the diagnosis and to plan appropriate multidisciplinary treatment. Therapy options depend on the gravity of the conditions as in CCF, ocular symptoms put the involved eyes at great risk. In patients with dural draining CCF and without ocular or cerebral signs, close observation may be adopted [12]. Occasionally, dural draining fistulas may favorably evolve to spontaneous closure, and this may especially occur after diagnostic angiography. In patients with dural CCF with low ocular or cerebral risk, a manual carotid-jugular manipulation/compression technique has also been adopted [12]. Although surgical treatment and/or radiotherapy have been used in the past, the current treatment of choice for direct or dural fistulas is transarterial or transvenous embolization of the fistula [13]. When possible, the best approach is through the inferior petrous sinus. If not accessible, the superior ophthalmic vein approach is adopted. 


\section{Conclusions}

Owing to the risk of vision loss in involved eyes, the ophthalmologist must be aware of the various clinical features of CCF. Diagnosis may be straightforward in cases with direct CCF draining directly into the ophthalmic veins or may be difficult, especially in cases of dural draining CCF where symptoms are subtle. Treatment options must be carefully considered and adopted in a timely manner, owing to the risks of vision loss associated with high IOP, vascular stasis, and ischemia of the retina and other ocular structures. A multidisciplinary approach of neuroradiologists, neurosurgeons, and ophthalmologists is advisable in complex cases.

\section{Statement of Ethics}

The study was conducted in accordance with the Tenets of the Declaration of Helsinki, and the patient provided consent to the publication of her case.

\section{Disclosure Statement}

The authors report no conflicts of interests.

\section{References}

1 De Keizer R: Carotid-cavernous and orbital arteriovenous fistulas: ocular features, diagnostic and hemodynamic considerations in relation to visual impairment and morbidity. Orbit 2003;22:121-142.

2 Barrow DL, Spector RH, Braun IF, Landman JA, Tindall SC: Classification and treatment of spontaneous carotid-cavernous sinus fistulas. J Neurosurg 1985;62:248-256.

3 Phelps CD, Thompson HS, Ossoinig KC: The diagnosis and prognosis of atypical carotid-cavernous fistula (red-eyed shunt syndrome). Am J Ophthalmol 1982;93:423-436.

4 Lambiase A, Abdolrahimzadeh S, Recupero SM: An update on intravitreal implants in use for eye disorders. Drugs Today (Barc) 2014;50:239-249.

-5 Scuderi GL, Cascone NC, Regine F, et al: Validity and limits of the rebound tonometer (Icare 5): clinical study. Eur J Ophthalmol 2011;21:251-257.

-6 Jorgensen JS, Guthoff R: The role of episcleral venous pressure in the development of secondary glaucoma. Klin Monatsbl Augenheikd 1988;193:471-475.

7 Cruciani F, Lorenzatti M, Nazzaro V, Abdolrahimzadeh S: Bilateral acute angle closure glaucoma and myopia induced by topiramate. Clin Ter 2009;160:215-216.

8 Scuderi GL, Cesareo M, Perdicchi A, Recupero SM: Standard automated perimetry and algorithms for monitoring glaucoma progression. Prog Brain Res 2008;77:99.

$\$ 9$ Iester M, Perdicci A, Capris E, et al: Comparison between discriminant analysis models and glaucoma probability score for the detection of glaucomatous optic nerve head changes. J Glaucoma 2008;17:535-540.

10 Recupero SM, Contestabile MT, Taverniti L, et al: Open-angle glaucoma: variations in the intraocular pressure after visual field examination. J Glaucoma 2003;12:114-118.

11 Michelessi M, Lucenteforte E, Oddone F, et al: Optic nerve head and fibre layer imaging for diagnosing glaucoma. Cochrane Database Syst Rev 2015;11:CD008803.

-12 Higashida RT, Hieshima GB, Halbach VV, Bentson JR, Godo K: Closure of carotid cavernous sinus fistulae by external compression of the carotid artery and jugular vein. Acta Radiol Suppl 1986;369:580-583.

13 Thèaudin M, Saint-Maurice JP, Chapot R, Vahedi K, Mazighi M, Vignal C, et al: Diagnosis and treatment of dural carotid-cavernous fistulas : a consecutive series of 27 patients. J Neurol Neurosurg Psychiatry 2007;78:174-179. 

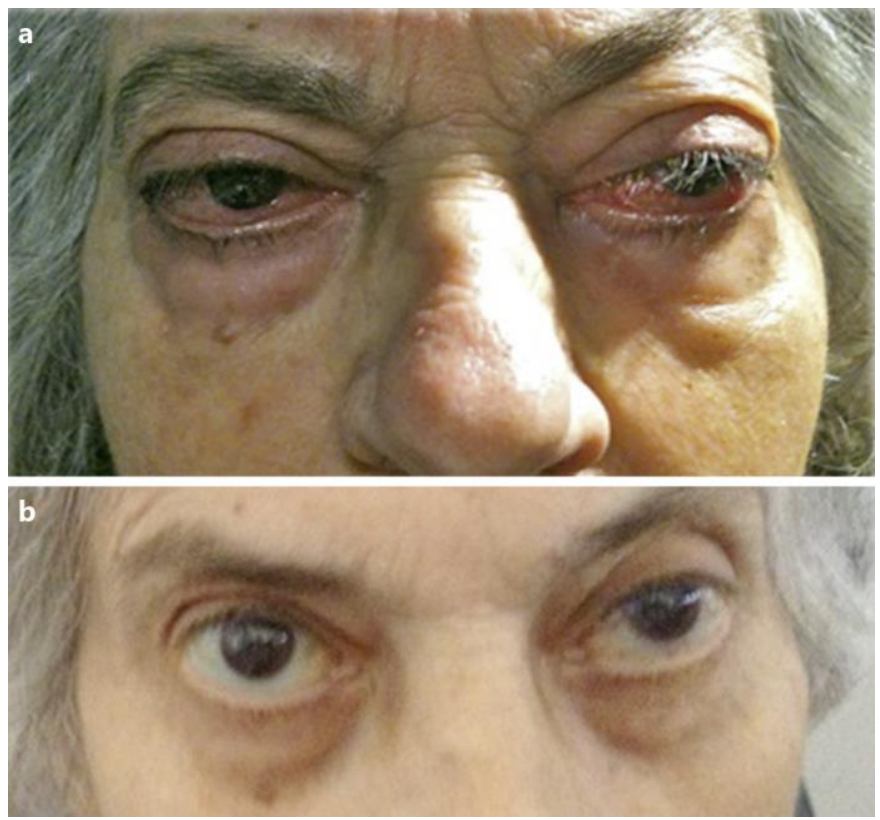

Fig. 1. a Frontal view of the patient showing bilateral axial proptosis, orbital edema, and injected chemotic conjunctiva with dilated corkscrew vessels, which is more severe in OD. b Postoperative appearance showing significant objective improvement of the proptosis and conjunctival chemosis. 
a
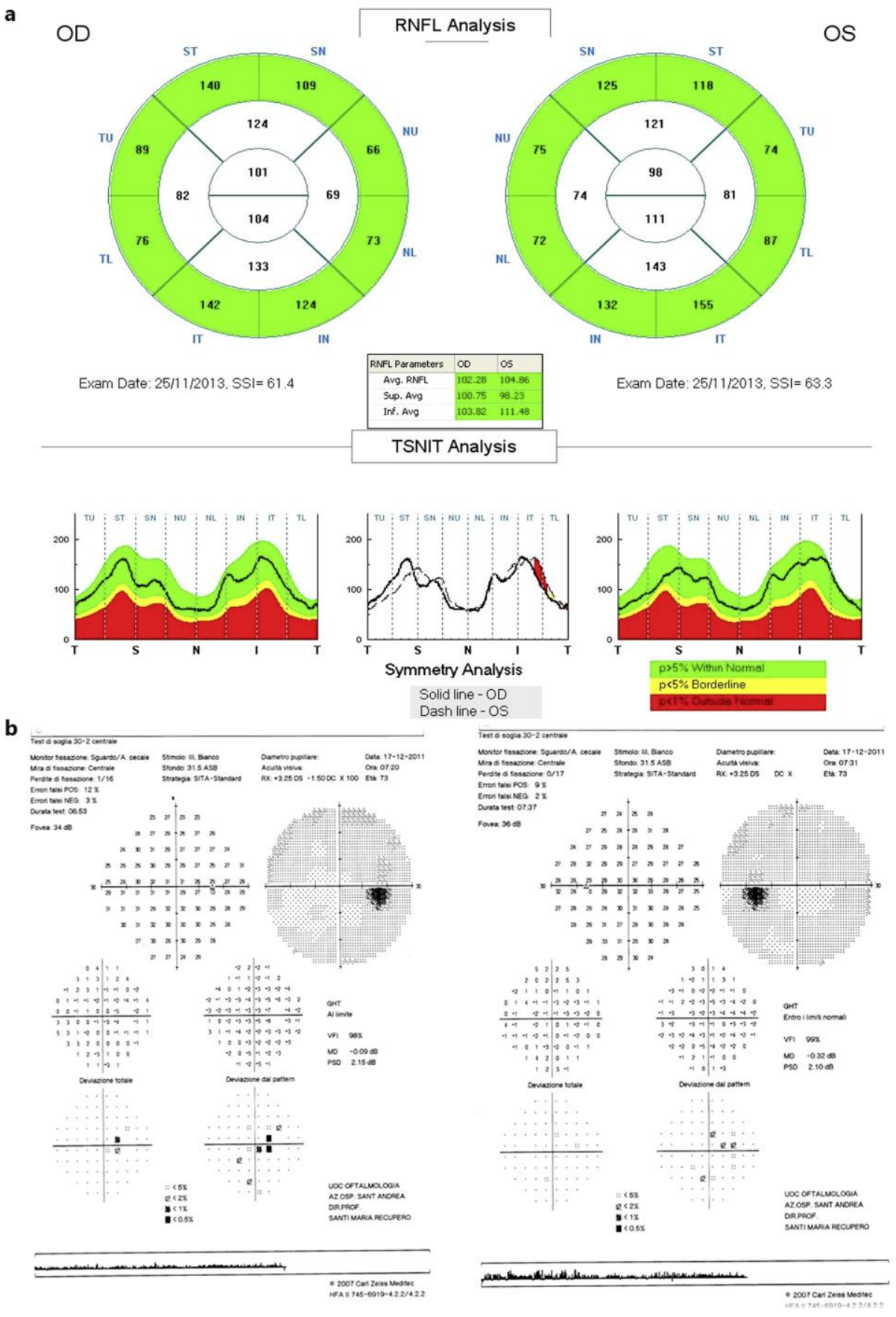

Fig. 2. a OCT scans showing normal peripapillary retinal nerve fiber thickness in OU. b Visual field analysis showing slight field defects mostly in OS with the bilateral normal glaucoma hemifield test. 


\section{Case Reports in Case Rep Ophthalmol 2016;7:296-302 \\ (C) 2016 The Author(s). Published by S. Karger AG, Basel www.karger.com/cop \\ Calafiore et al.: Glaucoma Management in Carotid Cavernous Fistula}
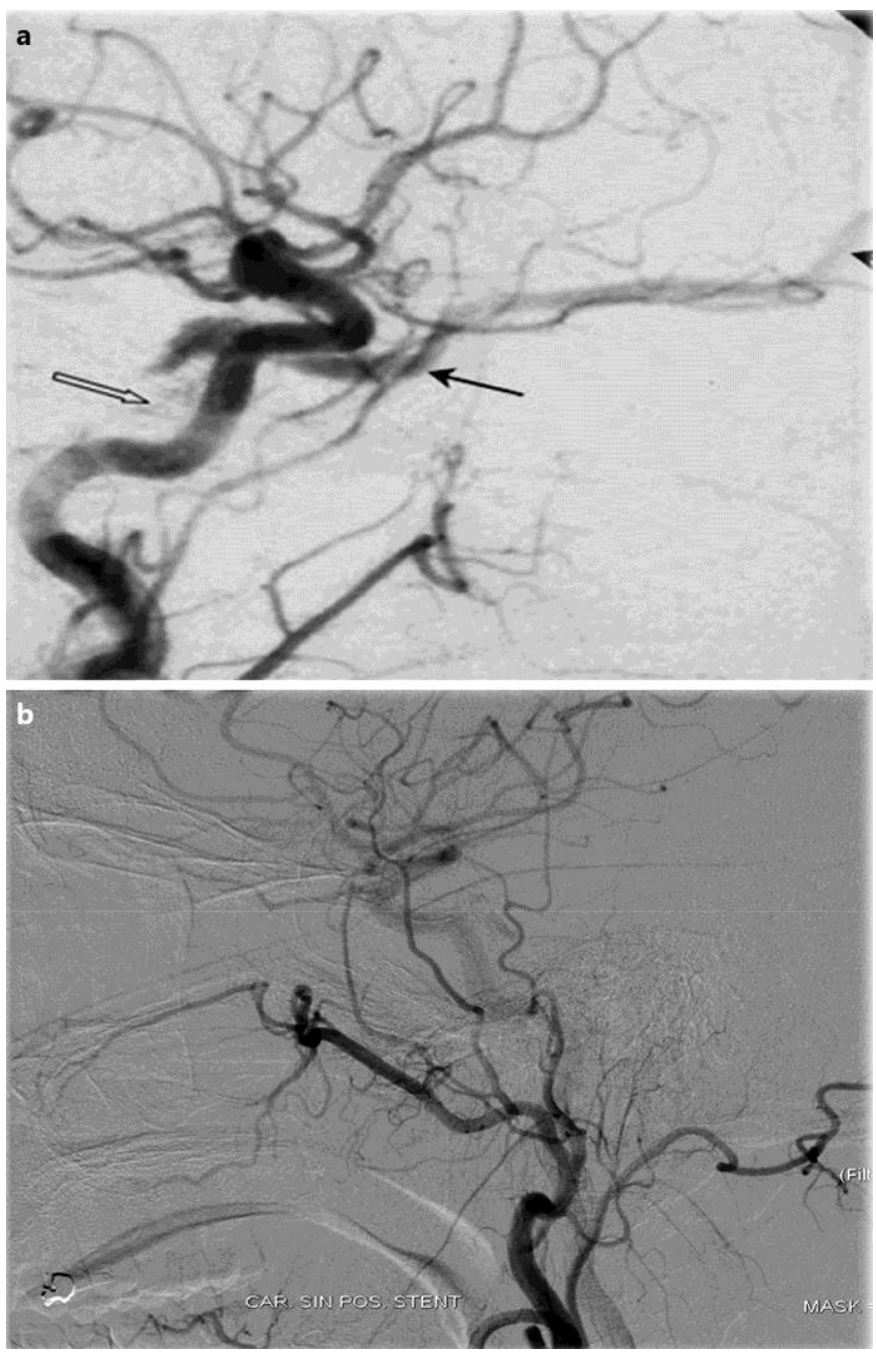

Fig. 3. a Angiogram of the left carotid artery demonstrates a carotid-cavernous fistula classified as Cognard grade 2 . White arrow = internal carotid artery segment; black arrow = arterialized superior ophthalmic vein. b Postoperative angiography showing exclusion of the CCF where the superior ophthalmic vein cannot be visualized. 